\title{
Canine Tooth
}

National Cancer Institute

\section{Source}

National Cancer Institute. Canine Tooth. NCI Thesaurus. Code C32258.

A single-cusped (pointed) and usually sing le-rooted tooth located between the incisors and premolars. 